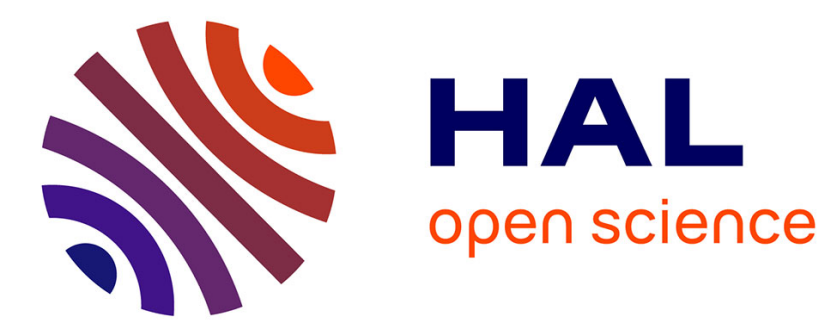

\title{
Determining the transition from juvenile to mature wood microfibril angle in lodgepole pine: a comparison of six different two-segment models
}

Wang, James Stewart

\section{- To cite this version:}

Wang, James Stewart. Determining the transition from juvenile to mature wood microfibril angle in lodgepole pine: a comparison of six different two-segment models. Annals of Forest Science, 2012, 69 (8), pp.927-937. 10.1007/s13595-012-0226-z · hal-00930874

\section{HAL Id: hal-00930874 https://hal.science/hal-00930874}

Submitted on 1 Jan 2012

HAL is a multi-disciplinary open access archive for the deposit and dissemination of scientific research documents, whether they are published or not. The documents may come from teaching and research institutions in France or abroad, or from public or private research centers.
L'archive ouverte pluridisciplinaire HAL, est destinée au dépôt et à la diffusion de documents scientifiques de niveau recherche, publiés ou non, émanant des établissements d'enseignement et de recherche français ou étrangers, des laboratoires publics ou privés. 


\title{
Determining the transition from juvenile to mature wood microfibril angle in lodgepole pine: a comparison of six different two-segment models
}

\author{
Mingliang Wang • James D. Stewart \\ Received: 15 May 2012 / Accepted: 9 July 2012 /Published online: 31 August 2012 \\ (C) INRA / Springer-Verlag France 2012
}

\begin{abstract}
- Context The transition of microfibril angle (MFA) values from juvenile to mature wood marks the change from variable, low-quality wood to stronger and more consistent wood that can produce higher value products.

- Aims We evaluate the utility of different statistical models that predict how much of a $\log$ is higher quality mature wood based on MFA.

- Methods MFA was measured from pith to bark at breast height in six lodgepole pine stands in western Canada. Six different forms of two-segment regression models were assessed to determine the point of transition (TP) in MFA from juvenile to mature wood.

- Results All six models provided useful and significant TP estimates. In the first segment (juvenile phase), the quadratic form produced the most conservative TPs, the linear form the least conservative, and the exponential form was intermediate. A linear second segment (mature phase) was only a
\end{abstract}

Handling Editor: Jean-Michel Leban

Contribution of the co-authors Mingliang Wang: responsible for the data analysis, modeling, and writing the first draft of the manuscript. James D. Stewart: responsible for the initiation, overall direction and management, and data collection for this study.

M. Wang

Foothills Research Institute,

Hinton, AB, Canada

J. D. Stewart $(\bowtie)$

Canadian Wood Fibre Centre, Canadian Forest Service,

Natural Resources Canada,

5320122 Street,

Edmonton, AB, Canada

e-mail: jstewart@NRCan.gc.ca

Present Address:

M. Wang

Warnell School of Forestry and Natural Resources,

University of Georgia,

Athens, GA, USA minor improvement over a constant. There were significant differences in MFA TP among some sites. Analyses of the relationships between TP and tree variables, e.g., DBH, height, were inconclusive.

- Conclusions Any of the six two-segment models can be used objectively to estimate MFA transition points; the choice of model will allow mill managers to manage risk in product out-turn.

Keywords Juvenile wood · Lodgepole pine · Mature wood · Microfibril angle $\cdot$ Segmented regression models .

Wood quality

\section{Introduction}

Lodgepole pine (Pinus contorta var. latifolia Doug. ex Loud.) is the most widely distributed conifer in the provinces of British Columbia and Alberta in western Canada. It is also one of the most valuable commercial species harvested in this range, is used in both lumber and pulp production, and has wood and fiber attributes that are suited for production of high-quality and high-value products. Understanding the transition between juvenile wood (JW) and mature wood (MW) is an important first step in understanding wood quality and the modeling of fiber attributes. The juvenile (pith-associated or crown-formed) wood is more variable and of lower quality than mature (bole-formed) wood, which is stronger and more consistent (Saranpää 2003), and thus can be used to produce higher quality products (e.g., machine stress-rated lumber). Knowing the point of transition from JW to MW wood allows the processor to optimize the use of a log, e.g., milling the JW for low-value commodity lumber (studs) or energy biomass, and milling high-value machine stress-rated lumber from the MW. Accurate transition point prediction from forest inventory information allows more efficient use of the log, 
production of less off-specification lumber, and lower costs because feedstock characteristics can be anticipated or selected early in the supply chain. We focus on the attribute of microfibril angle (MFA), which is defined as the angle of the cellulose microfibrils of the S2 layer of the secondary cell wall relative to the long axis of the cell (Butterfield 2003). MFA is also a key determinant of wood axial stiffness (Cave 1968) and longitudinal shrinkage (Harris and Meylan 1965) and is thus important to lumber quality. Mansfield et al. (2007, 2009) estimated transition points for MFA, as well as for density and fibre length, of fire-origin lodgepole pine trees grown in western Alberta and interior British Columbia. We examine MFA transition in a different subset of the lodgepole pine population, at six sites where long-term silviculture trials were established in natural fire-origin stands.

The demarcation between JW and MW is typically done by analyzing trends with physiological age (ring numbers (RN) from pith) of wood characteristics, including density (Clark and Saucier 1989; Tasissa and Burkhart 1998; Alteyrac et al. 2006; Clark et al. 2006; Mansfield et al. 2007, 2009), fiber length (FL) (Medzegue et al. 2007; Mansfield et al. 2009), and MFA (Bhat et al. 2001; Clark et al. 2006; Alteyrac et al. 2006; Mansfield et al. 2009), among others. However, with no clear definition of JW vs. MW, there are various transition determination methods available in the literature (for a good summary, see Goudie and Di Lucca 2004). One method that has received much attention is based on segmented regression analysis (Tasissa and Burkhart 1998; Bhat et al. 2001; Clark et al. 2006; Mansfield et al. 2007, 2009).

Our objective was to determine the JW-MW transition point based on one of the indicators of wood quality, MFA. Three pairs of two-segment models were considered, comparing their abilities to determine wood developmental phases (JW and MW) for MFA. The ability to predict the transition point from tree and site characteristics was also investigated. Even though the transition usually occurs in the first 20 years of growth, we wanted to check if there were characteristics that remained observable later in tree development that were related, statistically if not causally, to timing of the transition from JW to MW.

\section{Materials and methods}

\subsection{Data acquisition}

Core samples were taken at breast height $(\mathrm{BH} ; 1.3 \mathrm{~m})$ from 244 lodgepole pine trees in six different long-term silviculture research trials in the central foothills of Alberta and in southeastern British Columbia, in 2009. Sample trees were taken from selected treatments and from untreated controls. The treatments and other stand information are presented in Table 1, and more information can be found in Stewart et al.
(2006). In each treatment, 15 trees were selected at random from a subset of trees that were deemed to be representative of commercially viable trees, i.e., those within two standard deviations of the mean for height and diameter. This constraint was used because of the number of samples analyzed for each treatment, and a desire that results not be unduly influenced by data outliers.

Cores were taken either in the field with a $12-\mathrm{mm}$ diameter increment corer or sawn from a tree disk. Cores were sealed in plastic bags and kept at $4{ }^{\circ} \mathrm{C}$ when not being processed or transported. SilviScan analysis of the cores using X-ray diffractometry at $5 \mathrm{~mm}$ resolution was performed in the EvaluTree laboratory of FPInnovations in Vancouver (Defo et al. 2009). MFA was determined from the variance of the azimuthal X-ray diffraction profile of the cellulose perpendicular to the microfibril axis, and calculated according to Evans (1999) and Evans et al. (1999).

For simplicity, the interest at this stage is in characterizing (nearly) naturally grown trees and not in evaluating silviculture treatment effects. Therefore, some trees or observations were excluded from data analysis because of significant effects on MFA (and other fiber attributes) of some of the treatments imposed in the silviculture trials. Specifically, for the two BC sites, Cranbrook (CR) and Parson (PA), observations from 1993 (the time when the treatments were applied) and onwards were removed. Trees at these two sites were already more than 70 years old when thinned in 1993, an age well beyond the JW/MW transition point. For Teepee North (TN), Teepee Flat (TF), and MacKay (MK), trees from the 1,000 and 4,000 stems per hectare (sph) treatments, the 1,000 sph treatment, and the $750 \mathrm{sph}$ treatment, respectively, were excluded, due to obvious thinning effects on MFA development around (or shortly after) the treatment time, as judged by visual graphical checks. For McCardell (MC), no obvious effects of either thinning or fertilization on MFA were observed, and all trees were retained for analysis. Four additional trees were also removed because of their extreme irregularity. Ultimately, 195 out of the original 244 trees were used in data analysis.

\subsection{Segmented regression analysis}

Two-segment regression models have frequently been used to estimate the JW-MW transition point, in terms of the number of rings from the pith, for MFA (Bhat et al. 2001; Clark et al. 2006; Alteyrac et al. 2006; Mansfield et al. 2009). The general form of such models can be given as:

$y_{i}= \begin{cases}f_{1}\left(x_{i} ; \theta_{1}\right)+e_{i}, & x_{i} \leq x_{0} \\ f_{2}\left(x_{i} ; \theta_{2}\right)+e_{i}, & x_{i}>x_{0}\end{cases}$

where $y_{i}$ is the MFA measurement of the $i$ th ring from the pith, $x_{i}$ is the RN, $\theta_{1}$ and $\theta_{2}$ are parameter vectors, $x_{0}$ is the 
Table 1 Stand treatment and site descriptions for the six study sites

\begin{tabular}{|c|c|c|c|c|c|}
\hline Name/location & $\begin{array}{l}\text { Treatment } \\
\text { year }\end{array}$ & $\begin{array}{l}\text { Age at } \\
\text { treatment }\end{array}$ & Treatments used & $\begin{array}{l}\text { Nutrient } \\
\text { regime }\end{array}$ & $\begin{array}{l}\text { Moisture } \\
\text { regime }\end{array}$ \\
\hline \multicolumn{6}{|l|}{ Juvenile spacing trials } \\
\hline \multirow[t]{2}{*}{$\begin{array}{l}\text { Teepee Flat } 51^{\circ} 54.1^{\prime} \mathrm{N}, \\
115^{\circ} 11.2^{\prime} \mathrm{W}\end{array}$} & \multirow[t]{2}{*}{1967} & \multirow[t]{2}{*}{25} & $\begin{array}{l}8,000 \mathrm{sph}(1.1 \mathrm{~m} \text { spacing }) \\
4,000 \mathrm{sph}(1.6 \mathrm{~m} \text { spacing })\end{array}$ & \multirow[t]{2}{*}{ Medium rich } & \multirow[t]{2}{*}{ Mesic } \\
\hline & & & $1,000 \mathrm{sph}(3.2 \mathrm{~m}$ spacing $)$ & & \\
\hline \multirow[t]{2}{*}{$\begin{array}{l}\text { Teepee North } 51^{\circ} 53.8^{\prime} \mathrm{N}, \\
115^{\circ} 09.7^{\prime} \mathrm{W}\end{array}$} & \multirow[t]{2}{*}{1967} & \multirow[t]{2}{*}{25} & $\begin{array}{l}8,000 \mathrm{sph}(1.1 \mathrm{~m} \text { spacing }) \\
4,000 \mathrm{sph}(1.6 \mathrm{~m} \text { spacing })\end{array}$ & \multirow[t]{2}{*}{ Medium } & \multirow[t]{2}{*}{ Submesic } \\
\hline & & & $1,000 \mathrm{sph}(3.2 \mathrm{~m}$ spacing $)$ & & \\
\hline \multicolumn{6}{|l|}{ Mid-rotation thinning trial } \\
\hline \multirow[t]{2}{*}{$\begin{array}{l}\text { MacKay } 53^{\circ} 32.7^{\prime} \mathrm{N}, \\
115^{\circ} 32.3^{\prime} \mathrm{W}\end{array}$} & \multirow[t]{2}{*}{1954} & \multirow[t]{2}{*}{22} & $\begin{array}{l}750 \mathrm{sph} \\
2,600 \mathrm{sph}\end{array}$ & \multirow[t]{2}{*}{$\begin{array}{l}\text { Medium } \\
\text { poor }\end{array}$} & \multirow[t]{2}{*}{ Mesic } \\
\hline & & & 11,000 sph (unthinned) & & \\
\hline \multicolumn{6}{|l|}{ Late-rotation thinning trials } \\
\hline \multirow[t]{2}{*}{$\begin{array}{l}\text { Cranbrook } 49^{\circ} 25.0^{\prime} \mathrm{N}, \\
115^{\circ} 37.1^{\prime} \mathrm{W}\end{array}$} & \multirow[t]{2}{*}{1993} & \multirow[t]{2}{*}{65} & $\begin{array}{l}4 \mathrm{~m} \text { spacing }(625 \mathrm{sph}) \\
\text { Unthinned }(2,174 \mathrm{sph})\end{array}$ & \multirow[t]{2}{*}{$\begin{array}{l}\text { Medium } \\
\text { poor }\end{array}$} & \multirow[t]{2}{*}{ Mesic-submesic } \\
\hline & & & $\begin{array}{c}0 \text { or } 480 \mathrm{~kg} / \mathrm{ha} \\
(35-0-0-105)\end{array}$ & & \\
\hline $\begin{array}{c}\text { Parson } 50^{\circ} 59.3^{\prime} \mathrm{N} \\
116^{\circ} 41.2^{\prime} \mathrm{W}\end{array}$ & 1993 & 65 & $\begin{array}{l}5 \mathrm{~m} \text { spacing }(400 \mathrm{sph}) \\
\text { Unthinned }(1,375 \mathrm{sph})\end{array}$ & Medium & Mesic \\
\hline \multicolumn{6}{|c|}{ Factorial fertilization and thinning trials } \\
\hline \multirow[t]{2}{*}{$\begin{array}{l}\text { McCardell } 53^{\circ} 11.8^{\prime} \mathrm{N} \\
117^{\circ} 11.1^{\prime} \mathrm{W}\end{array}$} & \multirow[t]{2}{*}{1984} & \multirow[t]{2}{*}{40} & $\begin{array}{l}5,300 \text { sph unthinned } \\
2,100 \text { sph thinned }\end{array}$ & \multirow[t]{2}{*}{$\begin{array}{l}\text { Medium } \\
\text { poor }\end{array}$} & \multirow[t]{2}{*}{ Mesic } \\
\hline & & & $\begin{array}{c}0,180, \text { or } 360 \mathrm{~kg} / \mathrm{ha} \mathrm{N} \\
\text { (ammonium nitrate) }\end{array}$ & & \\
\hline
\end{tabular}

transition parameter, and $e$ is the error term. The two lines, represented respectively by $y=f_{1}(x)$ and $y=f_{2}(x)$, are joined at $x_{0}$.

One widely used model is the two-segment linear regression model, consisting of two simple linear regressions (termed here as LIN_LIN) constrained to share a joint transition point (Alteyrac et al. 2006; Clark et al. 2006; Mansfield et al. 2009). Two other two-segment models consist of either a first exponential or a first quadratic segment and a second constant (EXP_C, Q_C where EXP, Q, and $\mathrm{C}$ stand for exponential, quadratic, and constant, respectively (Bhat et al. 2001).

In this study, three more two-segment models were considered, LIN_C, EXP_LIN, and Q_LIN, all defined in Table 2 along with LIN_LIN and EXP_C. Q_C and/ or Q_LIN models were used in JW-MW transition analysis for wood density (Sauter et al. 1999; Mutz et al. 2004) and Q_C or LIN_C for FL (Peszlen 1994; Bhat et al. 2001). In contrast, no use of EXP_LIN was discovered in previous studies. The choice of the first

Table 2 The six two-segment regression models considered in this study

\begin{tabular}{llll}
\hline Model & $f_{1}(x)$ & $f_{2}(x)$ & Constraints \\
\hline LIN_C & $y=a+b x$ & $y=c$ & $c=a+b x_{0}$ \\
LIN_LIN & $y=a+b x$ & $y=a_{2}+b_{2} x$ & $a_{2}+b_{2} x_{0}=a+b x_{0}$ \\
EXP_C & $y=a e^{-b x}$ & $y=c$ & $c=a e^{-b x_{0}}$ \\
EXP_LIN & $y=a e^{-b x}$ & $y=a_{2}+b_{2} x$ & $a_{2}+b_{2} x_{0}=a e^{-b x_{0}}$ \\
Q_C & $y=a+b x+c x^{2}$ & $y=c^{\prime}$ & $c^{\prime}=a+b x_{0}+c x_{0}^{2}$ \\
& $y=a+b x+c x^{2}$ & $y=a_{2}+b_{2} x$ & $x_{0}=-\frac{b}{2 c}$ \\
Q_LIN & & & $a_{2}+b_{2} x_{0}=a+b x_{0}+c x_{0}^{2}$ \\
& & $x_{0}=-\frac{b}{2 c}$ & \\
\hline
\end{tabular}

Note: $f_{1}(x)$ applies for $x \leq x_{0}$ and $f_{2}(x)$ for $x \geq x_{0}$. The transition point of the two quadratic models can be obtained from the minimum point of the first quadratic segment, and for Q_C, it coincides with the smooth requirement (the first derivative of the quadratic segment being zero at the transition point) 
segment, linear, exponential, or quadratic, depends on the nature of MFA development in younger physiological ages (i.e., lower RN). The use of a constant value for the second segment in the three models (LIN_C, EXP C, and Q C) is based on the assumption that in MW, ring-specific MFA is stable. The more general case using a simple linear second segment allows for simple trends in the MFA developmental pattern of MW.

Table 2 presents the six two-segment models. Except for Q_C, which is both continuous and smooth at the joint point $x_{0}$, all the other models are continuous only. Except for the two quadratic models, the joint point $x_{0}$ is an individual parameter. For the second segment of the LIN_LIN model, parameterization in the form of $y=a+b x+\bar{c}\left(x-x_{0}\right)$ was adopted, as in Alteyrac et al. (2006) and Medzegue et al. (2007), because this form is more natural than that used in other previous studies (e.g., Tasissa and Burkhart 1998; Mansfield et al. 2009). The two alternative methods of parameterization are mathematically equivalent, related as $a_{2}=a-c x_{0}$ and $b_{2}=b+c$.

\subsection{Site-scale pooled data analysis and individual tree analysis}

Demarcation of transition points can be carried out at the site level (data for all trees pooled; e.g., Tasissa and Burkhart 1998; Clark et al. 2006) or at the individual tree level (e.g., Mansfield et al. 2007, 2009). All six models were applied at both the site and tree levels. The least squares fits of all six models were obtained using the SAS Proc NLIN.

For pooled data analysis at each site, $t$ tests (SAS Proc TTEST) were used to indirectly check the differences between each pair of models: LIN_C vs. LIN_LIN, EXP_C vs. EXP_LIN, and Q_C vs. Q_LIN. Differences in transition estimates were visually compared between these paired models and differences among the models.

The tree-specific estimates of transition ages provide an understanding of within-tree variability, and can be subjected to further analysis. Four kinds of analysis were considered. First, paired $t$ tests (SAS Proc TTEST) were used to compare the differences in transition estimates between each of the three paired models at each site and for all sites pooled. Second, the patterns of MFA development after the transition point were analyzed using the second linear segment of each of the three models, LIN_LIN, EXP_LIN, and Q_LIN. Third, analysis of variance (ANOVA) was performed to test for differences in transition estimates between sites for each of the six models using SAS Proc GLM. Last, correlation and regression analysis were used to investigate the relationships between tree transition points and tree variables (e.g., DBH and HT) using SAS Proc CORR and Proc GLM.

\section{Results}

\subsection{Site-scale pooled data analysis}

Table 3 presents two model fit measures, root mean squared error (RMSE), and adjusted $R^{2}$ for the six models fitted to the pooled data from each of the six sites. For the Parson site, LIN_LIN, EXP_LIN, and Q_LIN can be reduced to LIN_C, EXP_C, and Q_C, respectively, as indicated by $t$ tests (not reported). For the other five sites, for each of the three paired models (LIN_C vs. LIN_LIN, EXP_C vs. EXP_LIN, and Q_C vs. Q_LIN), the second linear segment improved model fits relative to the constant segment. For each given second segment (whether constant or linear), the quadratic model ranked first, the exponential second, and the linear third in terms of their adjusted $R^{2}$ values, although the differences were less than 0.01 in most cases.

Table 4 presents transition points determined by the six segmented models. For the Parson site, each of the three paired models (LIN_C vs. LIN_LIN, EXP_C vs. EXP_LIN, and Q_C vs. Q_LIN) obtained essentially the same transition points, consistent with the model fit statistics presented in Table 3. For the other five sites, and for each of the three paired models, using a constant for the second segment resulted in later transition points than using a linear segment, with the difference ranging between about 1 and 3 years depending on the site. For each model, substantial differences appeared between sites as indicated by the point of transition (TP) confidence intervals.

For each site, the most conservative models were the quadratic segmented models (Q_C and Q_LIN), which estimated transition points later than did the exponential segmented models (EXP_C and EXP_LIN), and both were later than the least conservative linear segmented models (LIN_C and LIN_LIN) (Fig. 1). The later transition points estimated by the quadratic models were as expected because the transition points were calculated as the minimum point of the quadratic curves. In contrast, the linear first segments were more suitable for modeling an abrupt change of MFA at younger physiological ages.

\subsection{Individual tree analysis}

Following Mansfield et al. (2009), the reliability of transition estimates from the six models was examined by graphical visual checking. In doing so, some outliers were excluded from the tree-level analysis, mostly due to the irregularity of the MFA-RN trend for the specific tree compared with the trend in the majority of trees. These irregularities were usually a large transient departure (bump) in the typically stable trend at the middle or the end of the profile. The other outliers were extreme transition values as indicated by statistical measures (e.g., box plots, Fig. 2). Outliers were considered to be those 
Table 3 Site-level model fit evaluation using RMSE in degrees (and adjusted $R^{2}$ ) for each of the six study sites
Note: for the Parson site, LIN LIN, EXP LIN, and Q LIN can be reduced to LIN_C, EXP_C, and Q_C, respectively

\begin{tabular}{lllllll}
\hline Site & Model & & & & \\
\cline { 2 - 6 } & LIN_C & LIN_LIN & EXP_C & EXP_LIN & Q_C & Q_LIN \\
\hline CR & $2.88(0.7279)$ & $2.86(0.7312)$ & $2.83(0.7373)$ & $2.82(0.7389)$ & $2.82(0.7391)$ & $2.81(0.7403)$ \\
PA & $2.52(0.7094)$ & $2.52(0.7095)$ & $2.48(0.7174)$ & $2.48(0.7172)$ & $2.48(0.7187)$ & $2.48(0.7185)$ \\
TN & $3.05(0.4660)$ & $3.00(0.4819)$ & $3.04(0.4706)$ & $3.00(0.4835)$ & $3.03(0.4738)$ & $3.00(0.4850)$ \\
TF & $4.54(0.5342)$ & $4.43(0.5561)$ & $4.50(0.5424)$ & $4.41(0.5604)$ & $4.49(0.5448)$ & $4.40(0.5617)$ \\
MK & $3.00(0.6074)$ & $2.97(0.6162)$ & $2.96(0.6168)$ & $2.94(0.6228)$ & $2.95(0.6212)$ & $2.93(0.6254)$ \\
MC & $3.38(0.6827)$ & $3.34(0.6890)$ & $3.32(0.6933)$ & $3.30(0.6971)$ & $3.30(0.6960)$ & $3.29(0.6992)$ \\
\hline & & & & & &
\end{tabular}

points beyond the 1 st or 99 th percentiles. Table 5 presents descriptive statistics of the transition estimates obtained from the six models at the six sites.

Individual tree-level analysis (Table 5) found differences in transition estimates between paired models (LIN_C vs. LIN LIN, EXP C vs. EXP LIN, and Q C vs. Q LIN), and differences among sites for each given model. The trend in the differences among the EXP, LIN, and Q models were consistent across sites, and remained so at the tree level. Therefore, tree-level data analysis performed at each site, or pooled across sites, focused on testing for the differences between the paired models, and the differences among sites. Because the TN site had only a small number of trees (six to eight, depending on the model), this site was excluded from site-specific tree-level analysis but kept in the pooled site analysis where appropriate.

By comparing the site-level transition points estimated in the pooled data analysis (Table 4) to the mean of individual tree estimates (Table 5) for each site, some discrepancies appeared for some models at some sites. The differences between pooled and tree-based mean estimates of transition points ranged from about -0.6 ring to about 2.1 rings, with the mean difference about $0.3( \pm 0.6)$ rings, across sites and models. This is mostly due to differing data analysis; the pooled data analysis estimated the transition point of the single mean MFA-RN curve for a given site, whereas the individual tree analysis estimated the mean of the transition point of the individual tree MFA-RN trajectories included in the site. Nonetheless, the differences were probably not significant because in general the $95 \%$ confidence intervals of both the pooled and tree-based mean estimates largely overlapped.

\subsubsection{Comparison between model pairs}

The paired $t$ test was used to compare the difference in transition estimates among each of the three paired models: LIN_C vs. LIN_LIN, EXP_C vs. EXP_LIN, and Q_C vs. Q_LIN, at each site and for all sites pooled. Although for some sites the differences were not significant, significant differences were found between each pair of models when data were pooled over all sites. The comparison results for the TN site should be treated with caution because of the very few observations available for the test. Nonetheless, the mean differences between paired models were small, less than one ring in general, so even though the differences are statistically significant, practically they make no difference.

The mean differences between pairs of tree-based models at each site (Table 6) were smaller than the mean differences found in the pooled, site-level estimates between the paired models (Table 4) for which more than one-ring differences were usually observed. This seeming contradiction is due to the differing data analysis, analogous to the explanation for the discrepancy between the site-level transition point estimate and the mean of the individual tree estimates in the section above. Some trees were eliminated from the treelevel analysis where reasonable fits could not be obtained. There were some discrepancies between the mean differences (Table 6) and the differences in means (implied in
Table 4 Site-level estimates for transition points (and standard errors) expressed as ring numbers for each of the six study sites

\begin{tabular}{lrrlrll}
\hline Site & \multicolumn{7}{l}{ Model } \\
\cline { 2 - 7 } & \multicolumn{1}{l}{ LIN_C } & \multicolumn{1}{c}{ LIN_LIN } & \multicolumn{1}{l}{ EXP_C } & \multicolumn{1}{c}{ EXP_LIN } & Q_C & Q_LIN \\
\hline CR & $14.5(0.15)$ & $13.6(0.17)$ & $16.7(0.20)$ & $15.7(0.23)$ & $20.7(0.29)$ & $19.9(0.33)$ \\
PA & $12.7(0.25)$ & $12.6(0.26)$ & $14.5(0.31)$ & $14.4(0.36)$ & $17.9(0.46)$ & $17.9(0.52)$ \\
TN & $9.7(0.51)$ & $8.4(0.50)$ & $10.8(0.62)$ & $9.4(0.65)$ & $14.3(0.99)$ & $12.2(1.10)$ \\
TF & $10.7(0.33)$ & $8.7(0.35)$ & $12.5(0.44)$ & $10.3(0.47)$ & $15.5(0.64)$ & $12.9(0.72)$ \\
MK & $11.9(0.25)$ & $10.7(0.26)$ & $13.7(0.31)$ & $12.4(0.34)$ & $17.8(0.48)$ & $16.0(0.52)$ \\
MC & $13.5(0.18)$ & $12.4(0.19)$ & $15.4(0.23)$ & $13.8(0.27)$ & $19.0(0.34)$ & $17.6(0.40)$ \\
\hline
\end{tabular}


Fig. 1 Observed (mean) and fitted MFA trends vs. RN, with predicted transition points superimposed on the curves, for the Cranbrook site. The curves for observed data represent the same data in all cases. LIN, EXP, and Q indicate the first segments of each of the three paired models (LIN_C and LIN_LIN), (EXP C and EXP_LIN), and (Q_C and Q_L $\overline{I N}$ ), respectively, and C and LIN the second segments. For clarity, the observed MFA trend is the single mean MFA curve averaged over the trees, whereas the fitted trends are obtained from fitting models to the entire raw data at site $\mathrm{CR}$

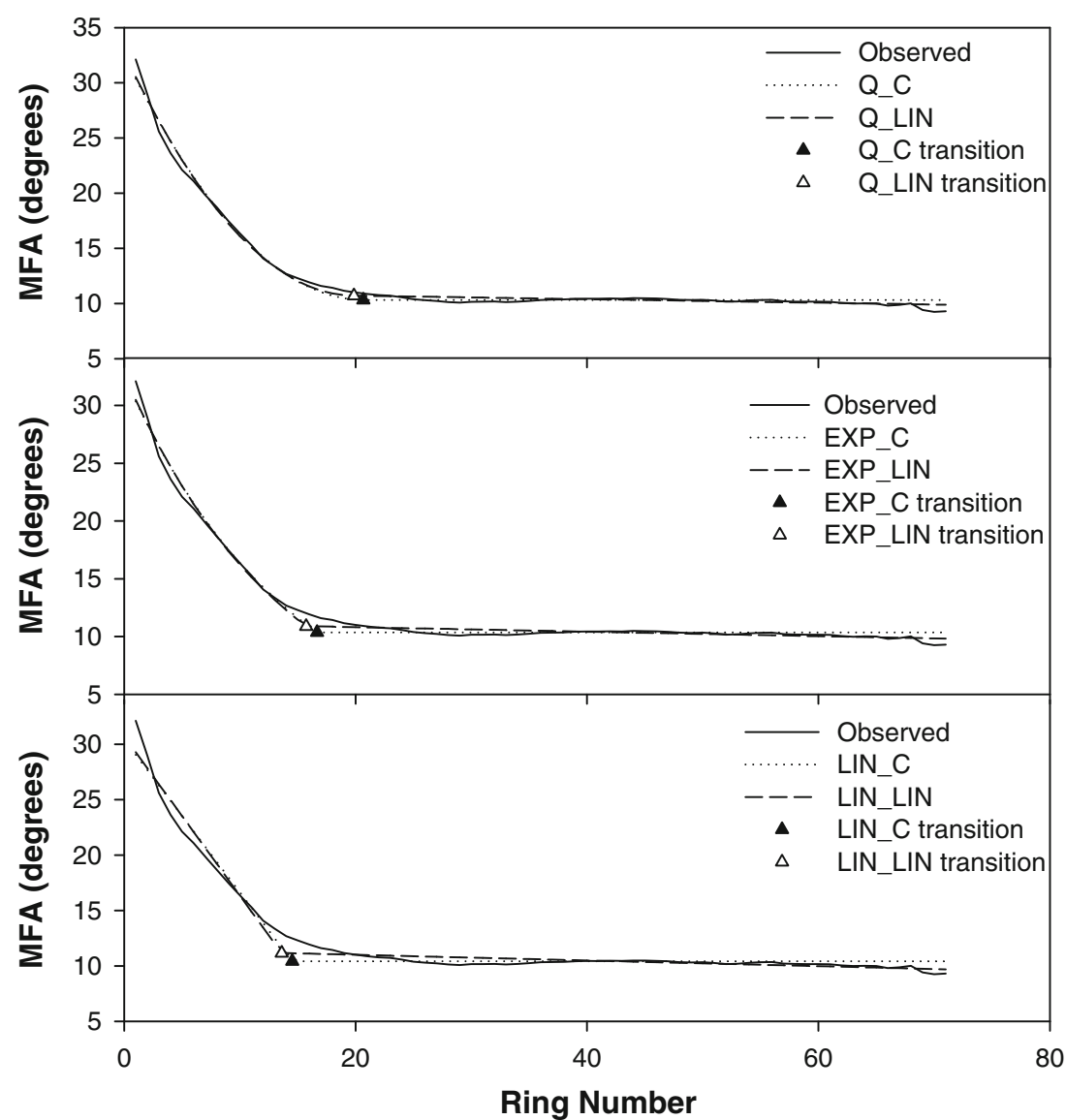

Table 5) for some paired models, although they were very small (mostly less than half a ring). This is because some transition estimates do not appear as outliers for each of the two paired models, but their differences do, and vice versa. Thus, for the comparison between paired models, the

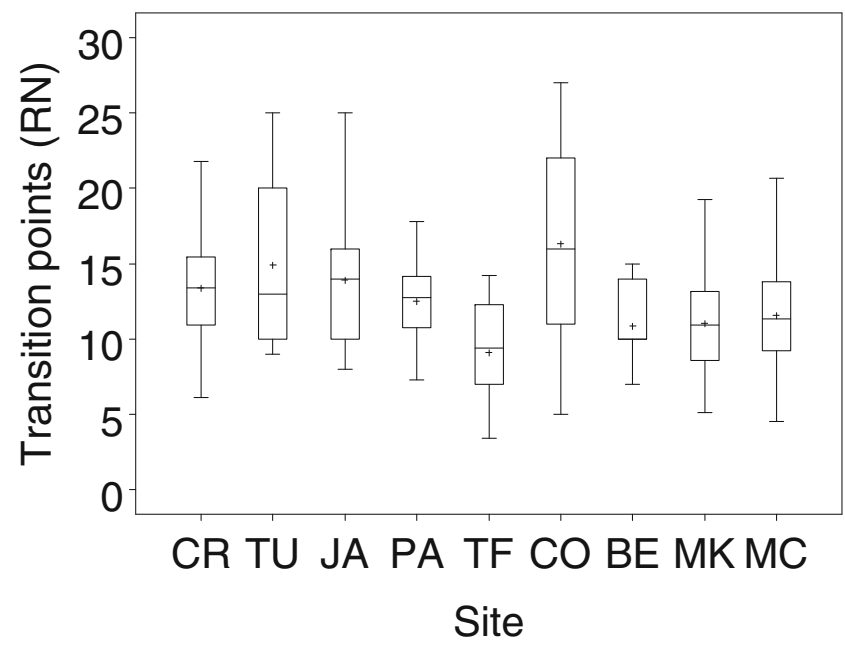

Fig. 2 Box plots of mean tree-level transition estimates obtained by model LIN_LIN for five CFS sites (CR, PA, TF, MK, and MC) and four sites (TU, JA, BE, and CO) of Mansfield et al. 2009. Plots are arranged left to right with increasing latitude of the site analysis of mean differences in the transition point estimates (Table 6) should be more reliable.

\subsubsection{Post-transition trends in MFA}

To complement the tests for the differences in transition point estimates between each of the three paired models, patterns of MFA development after the transition point were investigated, which can be determined by analyzing the second linear segment of each of the three models, LIN LIN, EXP_LIN, and Q_LIN. The slope of the second linear segment was tested to see if it was significantly different from zero; if not, the trend is constant; otherwise, the trend is either decreasing (negative slope) or increasing (positive slope). Table 7 presents the frequency distribution of the three MFA trends for the three models at each site and for pooled sites.

In general, for all three models, most trees showed decreasing trends and more trees showed constant trends than increasing trends. The distribution of the three patterns depended on the chosen model: for the LIN_LIN model, more than one half of the trees showed the decreasing trend, less than one-third the constant, and about one-seventh the increasing trend; for Q_LIN, less than one half showed the decreasing trend, more than one third the constant, and about one fifth the increasing 
Table 5 Tree-level transition point estimates, expressed as ring numbers, for six models at each of six sites (mean $(N)$, standard deviation (SD), minimum (Min), and maximum (Max))

\begin{tabular}{|c|c|c|c|c|c|c|c|c|c|c|c|c|}
\hline Site & Model & Number & Mean & $\mathrm{SD}$ & Min & Max & Model & Number & Mean & $\mathrm{SD}$ & Min & $\operatorname{Max}$ \\
\hline $1 \mathrm{CR}$ & \multirow[t]{6}{*}{ LIN_C } & 57 & 13.9 & 3.5 & 6.4 & 22.2 & \multirow[t]{6}{*}{ LIN_LIN } & 56 & 13.4 & 3.5 & 6.1 & 21.8 \\
\hline $2 \mathrm{PA}$ & & 20 & 12.6 & 3.1 & 7.2 & 19.5 & & 20 & 12.5 & 2.6 & 7.3 & 17.8 \\
\hline $3 \mathrm{TN}$ & & 8 & 9.8 & 4.0 & 5.5 & 17.8 & & 7 & 8.9 & 2.3 & 6.0 & 12.4 \\
\hline $4 \mathrm{TF}$ & & 18 & 10.0 & 2.9 & 4.1 & 13.9 & & 19 & 9.1 & 3.2 & 3.4 & 14.2 \\
\hline $5 \mathrm{MK}$ & & 27 & 11.6 & 3.9 & 5.6 & 20.6 & & 29 & 11.1 & 3.4 & 5.1 & 19.3 \\
\hline $6 \mathrm{MC}$ & & 57 & 12.6 & 3.9 & 6.5 & 22.1 & & 58 & 11.6 & 3.8 & 4.6 & 20.7 \\
\hline $1 \mathrm{CR}$ & \multirow[t]{6}{*}{ EXP_C } & 57 & 16.3 & 4.5 & 8.6 & 25.8 & \multirow[t]{6}{*}{ EXP_LIN } & 56 & 15.7 & 4.6 & 7.4 & 26.4 \\
\hline $2 \mathrm{PA}$ & & 20 & 14.3 & 3.9 & 7.6 & 23.0 & & 20 & 14.3 & 3.0 & 8.3 & 20.5 \\
\hline $3 \mathrm{TN}$ & & 8 & 10.9 & 4.6 & 6.2 & 20.0 & & 7 & 9.9 & 2.7 & 6.0 & 13.8 \\
\hline $4 \mathrm{TF}$ & & 18 & 12.4 & 5.5 & 4.4 & 25.5 & & 19 & 10.4 & 3.9 & 4.4 & 17.3 \\
\hline $5 \mathrm{MK}$ & & 27 & 13.1 & 4.7 & 6.0 & 24.4 & & 28 & 12.9 & 4.5 & 5.3 & 23.3 \\
\hline $6 \mathrm{MC}$ & & 58 & 14.8 & 5.1 & 7.4 & 26.6 & & 57 & 13.5 & 4.6 & 4.5 & 25.6 \\
\hline $1 \mathrm{CR}$ & \multirow[t]{6}{*}{ Q_C } & 56 & 20.1 & 5.5 & 9.6 & 31.4 & \multirow[t]{6}{*}{ Q_LIN } & 57 & 19.5 & 6.0 & 8.4 & 35.9 \\
\hline $2 \mathrm{PA}$ & & 20 & 17.8 & 4.7 & 9.3 & 28.2 & & 20 & 18.0 & 4.1 & 9.9 & 25.8 \\
\hline $3 \mathrm{TN}$ & & 6 & 12.7 & 3.4 & 7.8 & 17.4 & & 6 & 12.3 & 3.5 & 7.7 & 17.0 \\
\hline $4 \mathrm{TF}$ & & 15 & 13.4 & 4.1 & 5.0 & 19.5 & & 18 & 12.5 & 4.3 & 5.0 & 20.0 \\
\hline $5 \mathrm{MK}$ & & 27 & 16.5 & 6.1 & 7.3 & 31.0 & & 27 & 15.8 & 5.6 & 6.9 & 28.2 \\
\hline $6 \mathrm{MC}$ & & 56 & 18.0 & 6.0 & 9.2 & 32.4 & & 55 & 16.7 & 5.8 & 6.6 & 31.9 \\
\hline
\end{tabular}

trend; and the EXP LIN results were in between those of the other two models. However, there was no indication of significant association among the three patterns and tree characteristics (e.g., DBH, height).
Regardless of the three patterns, the mean slope values of the three models were about $-0.03,-0.01$, and -0.01 for LIN_LIN, EXP_LIN, and Q_LIN, respectively, suggesting that at least for both EXP_LIN and Q_LIN, the models
Table 6 Mean differences in tree-level transition point estimates among each of the three pairs of models
Results of $t$ tests are presented for individual sites and for all data pooled

\begin{tabular}{llrrrrr}
\hline Model pair & Site & Number & Mean & SD & $t$ value & $p$ value \\
\hline LIN_C and LIN_LIN & CR & 57 & 0.5 & 1.4 & 2.77 & 0.0075 \\
& PA & 19 & 0.3 & 1.4 & 1.02 & 0.3193 \\
& TN & 7 & 1.4 & 3.1 & 1.23 & 0.2636 \\
& TF & 17 & 0.9 & 1.2 & 2.84 & 0.0119 \\
& MK & 27 & 0.5 & 1.9 & 1.47 & 0.1547 \\
& MC & 59 & 0.8 & 1.8 & 3.40 & 0.0012 \\
EXP_C and EXP_LIN & All & 186 & 0.7 & 1.7 & 5.33 & $<0.0001$ \\
& CR & 57 & 0.5 & 1.8 & 2.20 & 0.0319 \\
& PA & 19 & 0.3 & 1.7 & 0.83 & 0.4172 \\
& TN & 6 & 0.3 & 1.8 & 0.43 & 0.6848 \\
& TF & 16 & 0.6 & 1.8 & 1.37 & 0.1910 \\
& MK & 27 & 0.6 & 2.4 & 1.40 & 0.1727 \\
& MC & 56 & 1.2 & 2.4 & 3.53 & 0.0008 \\
Q_C and Q_LIN & All & 181 & 0.7 & 2.1 & 4.60 & $<0.0001$ \\
& CR & 57 & 0.4 & 2.3 & 1.37 & 0.1754 \\
& PA & 19 & 0.3 & 1.9 & 0.78 & 0.4457 \\
& TN & 6 & 0.4 & 2.2 & 0.41 & 0.7001 \\
& TF & 16 & 0.7 & 1.7 & 1.67 & 0.1152 \\
& MK & 27 & 0.7 & 3.1 & 1.15 & 0.2621 \\
& MC & 57 & 0.8 & 2.9 & 2.13 & 0.0375 \\
& All & 182 & 0.6 & 2.5 & 3.20 & 0.0016 \\
\hline
\end{tabular}


Table 7 Frequencies of the three patterns (decreasing, constant, and increasing) of MFA development after transition points, for three models at each site and pooled sites

\begin{tabular}{llrrrr}
\hline Model & Site & Slope $<0$ & Slope $=0$ & Slope $>0$ & Total \\
\hline LIN_LIN & CR & 35 & 14 & 9 & 58 \\
& PA & 11 & 4 & 5 & 20 \\
& TN & 5 & 1 & 1 & 7 \\
& TF & 13 & 4 & 2 & 19 \\
& MK & 15 & 7 & 7 & 29 \\
& MC & 34 & 22 & 4 & 60 \\
& All & 113 & 52 & 28 & 193 \\
& CR & 29 & 18 & 11 & 58 \\
& PA & 9 & 6 & 5 & 20 \\
& TN & 4 & 2 & 1 & 7 \\
& TF & 11 & 6 & 2 & 19 \\
& MK & 15 & 6 & 7 & 28 \\
& MC & 26 & 26 & 8 & 60 \\
& All & 94 & 64 & 34 & 192 \\
& CR & 24 & 21 & 13 & 58 \\
& PA & 9 & 6 & 5 & 20 \\
& TN & 3 & 1 & 2 & 6 \\
& TF & 10 & 7 & 2 & 19 \\
& MK & 13 & 8 & 7 & 28 \\
& MC & 26 & 26 & 8 & 60 \\
& All & 85 & 69 & 37 & 191 \\
\hline \multirow{5}{*}{ EIN } & & & &
\end{tabular}

could be reduced to EXP_C and Q_C, respectively. From a modeling point of view (for describing the overall MFA-RN trends), the assumption that MFA values approach a lower asymptote as RN approaches large values is supported by previous studies on modeling MFA-RN trends (e.g., Jordan et al. 2005).

\subsubsection{Relationship between tree transition points and tree variables}

Correlation and regression analysis were used to investigate the relationship between tree transition points and tree variables, including diameter at $\mathrm{BH}(1.3 \mathrm{~m}$; $\mathrm{DBH})$, total tree height $(\mathrm{HT})$, slenderness coefficient $(\mathrm{SC}=\mathrm{HT} / \mathrm{DBH})$, basal area of all trees in the plot larger than the subject tree (BAL), crown radius, crown length, and others. Tree measurements were taken in 2009. Except at the MC site, there was no significant correlation between transition estimates obtained from any of the six models and tree variables. At site $\mathrm{MC}$, $\mathrm{DBH}, \mathrm{SC}$, and BAL were all significantly correlated with transition points estimated by each model, mostly at the 0.05 level but not the 0.01 level; the correlation coefficients were all about 0.3 . Regression analysis showed that only one of the three variables was needed, but when crown radius was further included in the models, fit significantly improved $\left(R^{2}\right.$ increased from about 0.08 to 0.12 (BAL), 0.14 (SC), and $0.18(\mathrm{DBH})$ ), although the reasons for why this should be so are not clear, when crown radius alone was not significantly correlated with transition points. When the two largest estimates $(\mathrm{RN}>30)$ for site $\mathrm{MC}$, which were identified as outliers by box plots, were excluded, correlation with $\mathrm{DBH}$ and BAL was no longer significant, thus the results of correlation analysis at this site are inconclusive. Further study would be needed to determine the factors affecting the observed differences in transition points at the tree and stand level, especially from a physiological point of view.

\subsubsection{Site difference in MFA transition points}

Overall significant differences in TP estimates were found among the five sites (excluding TN) for each model at the level of $p=0.05$ (ANOVA; Table 8). Multiple paired comparisons showed significant differences between some paired sites; which pairs depended on the model chosen (detailed results not reported). Multiple paired comparisons indicated significant differences between $\mathrm{CR}$ and TF, CR and $\mathrm{MK}, \mathrm{CR}$ and $\mathrm{MC}$, and $\mathrm{PA}$ and $\mathrm{TF}$.

\section{Discussion}

\subsection{Site differences in MFA transition points}

Based on site-scale pooled data analysis, the site-level MFA TP estimates obtained by model LIN_LIN ranged from 8.4 rings at site $\mathrm{TN}$ to 13.6 at site $\mathrm{CR}$ (Table 4). These findings, which correspond well to the means of individual tree estimates (Table 5), agree with those of Clark et al. (2006) where the regional LIN_LIN TP estimates varied between 8.9 and 13.4 rings for loblolly pine.

Analysis of individual tree TP estimates across sites indicated significant site differences among the five sites tested in this study for each model. The LIN_LIN result in particular contrasts with Mansfield et al. (2009), where no significant differences were found among the four lodgepole pine sites in BC (southern interior-Tunkwa Lake (TU) and

Table 8 ANOVA results for site differences among transition point estimates

\begin{tabular}{lcccc}
\hline Model & Model $d f$ & Error $d f$ & $F$ value & $p$ value \\
\hline LIN_C & 4 & 174 & 4.94 & 0.0009 \\
LIN_LIN & 4 & 177 & 6.31 & 0.0001 \\
EXP_C & 4 & 175 & 3.35 & 0.0113 \\
EXP_LIN & 4 & 175 & 5.92 & 0.0002 \\
Q_C & 4 & 169 & 5.03 & 0.0008 \\
Q_LIN & 4 & 172 & 6.39 & 0.0001 \\
\hline
\end{tabular}


Jamieson Creek (JA); central interior-Bellos Lake (BE) and Cottonwood River (CO)). To analyze MFA TPs for lodgepole pine at a large scale, 55 tree-based MFA TPs at the four sites of Mansfield et al. (2009, Table 2) were combined with our individual tree estimates. There were 60 trees available in Mansfield et al. (2009), 15 trees for each site, but three of them had no reasonable TP estimates, and two (B45 and J92) were identified as outliers and therefore excluded. Box plots of the MFA TPs at the nine sites are presented in Fig. 2, generally from the south to the north. Overall, ANOVA showed significant site differences, however, for each of the two subgroups, the four southern sites (CR, TU, JA, and PA) and the three northern sites (BE, MK, and $\mathrm{MC}$ ), no significant differences were found. For the nine sites, the averaged tree TPs ranged between about 9 to about 16 rings. The TF site had obviously lower estimates than all other sites, probably because tree crowns lifted past $1.3 \mathrm{~m}$ very early due to the high competition among trees induced by very high initial tree density, as high as 250,000 stems per hectare in 1967 when the Teepee spacing experiment was established and the trees were about 25 years old.

\subsection{Transition relative to crown variables}

The transition from JW to MW is related to the position of the crown relative to the part of the stem in question. The MW forms once the crown base has risen above that point (Larson 1969; Larson et al. 2001). For our BH samples, the transition should occur early in stand development as the crowns lift past $1.3 \mathrm{~m}$. This crown lift (and thus the JWMW transition) should occur earlier where the stand density is higher. Crown lift would also be influenced by development of neighboring trees that shade the crown of the tree in question. Thus transition points should be related to the tree's competitive status within the stand, as suggested by results for the MC site, where transitions were correlated to the three tree variables. The relatively weak correlations found in the MC site and the lack of correlation in other sites may be attributed to the time elapsed between the time when the crown base was at $1.3 \mathrm{~m}$ (the 1950s or 1960s) and the time of measurement of the tree variables (2008-2009). A stronger correlation between transition points and $\mathrm{DBH}, \mathrm{SC}$, or BAL would be expected if they were measured at a time closer to the time of the transition. When the earliest measurements of DBH (and hence BAL) from 1989 were used, there was about a 0.1 increase in correlation coefficient for $\mathrm{DBH}$, and only a very slight increase for BAL.

\subsection{Operational use of transition points}

To make the results of this study of operational value, we need to extend our analysis in at least two more aspects, the

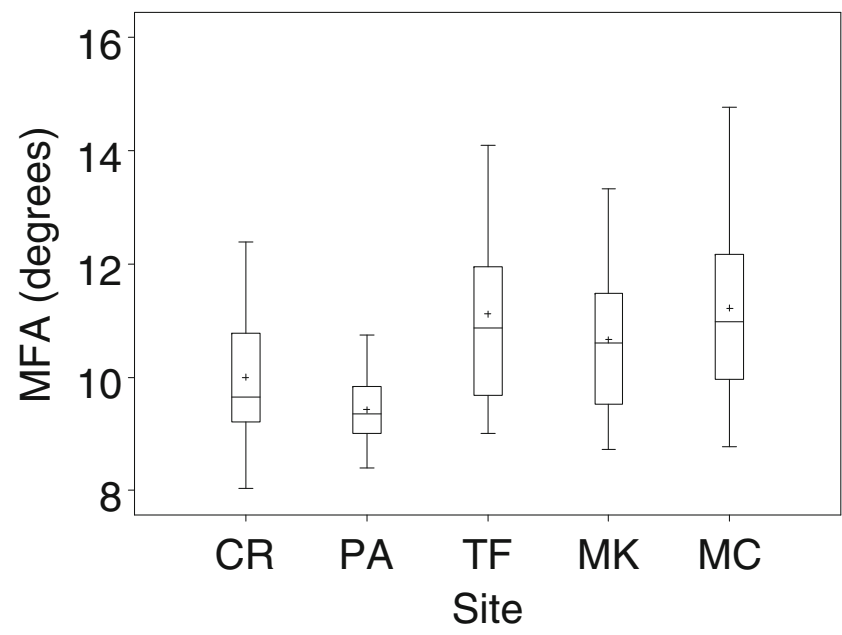

Fig. 3 Box plots of tree-averaged MFA over rings after transition points estimated by model LIN_LIN for five CFS sites

averaged MFA of the mature wood after the TP, and the cumulative ring width (RW) from the pith to the TP. The analysis of mature wood MFA shows its variations among trees and sites, and demonstrates the potential for using segmented models for demarcating JW and MW as a simple tool to facilitate the allocation of wood of different quality to different products. The computation of cumulative RW from the pith to the TP will facilitate operational use of the analysis of transition points for wood processing in mills.

A full report on the two kinds of subsequent analysis based on all six of the models used in this study would be unnecessarily redundant, so the LIN_LIN model was chosen

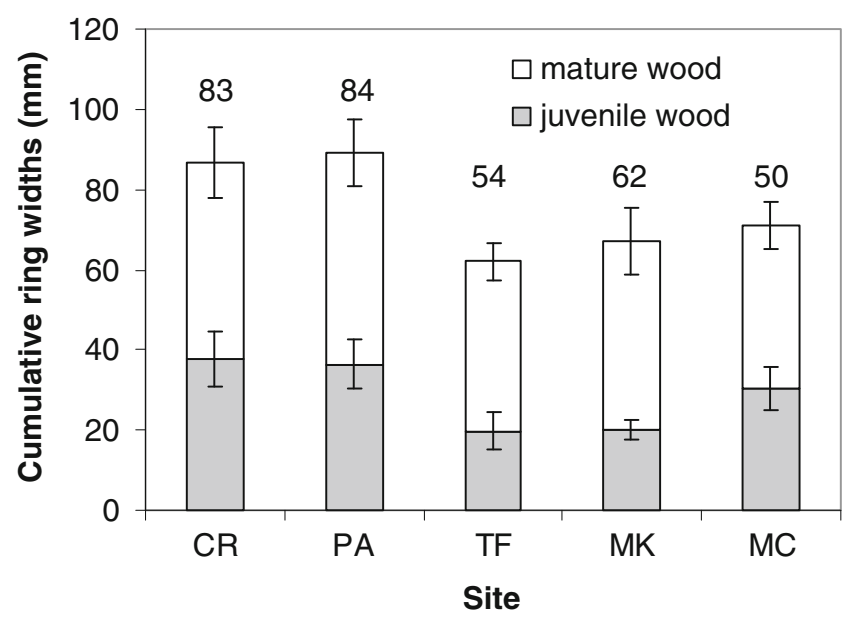

Fig. 4 Proportions of juvenile (grey) and mature wood (white) as measured by cumulative ring widths along the radius from pith to bark for five sites. The transition point between juvenile and mature wood was estimated by the LIN_LIN model. Standard error bars are shown, and the mean tree ages at breast height are noted above the bars 
for illustration. Figure 3 presents mature wood MFA variations among trees and among sites. ANOVA indicated significant differences in mature MFA among the five sites. For a particular wood product, if its MFA requirement were, say, $10^{\circ}$ at maximum, the LIN_LIN segmented model would be appropriate in determining TPs only for the two $\mathrm{BC}$ sites (CR and PA), and not for the other three sites (TF, MK, and MC). It should be noted that the minimum MFA threshold for a specific wood product or grade may be below that corresponding to the TP as determined by our models. In such a case, predicting the number of rings to reach that specific MFA value from the models may be preferred.

Figure 4 presents the mean (and SE) cumulated RW from the pith to the TP, along with whole core RW, for the five sites. A mill manager would be better able to set up the saw or peeler line to optimize product value by using the estimated tree TPs in terms of distances from the pith (between 35 and $40 \mathrm{~mm}$ for CR and PA, about $20 \mathrm{~mm}$ for $\mathrm{TF}$ and $\mathrm{MK}$, and about $30 \mathrm{~mm}$ for $\mathrm{MC}$, on average) (Fig. 4). The variation in the proportion of JW to MW can be determined from the tree-level estimates. Of course, this proportion depends not only on site, but also on tree size in terms of DBH or age because for a given tree at a given height, JW will be finally "fixed" at the TP while MW will continue to grow (Fig. 4).

\section{Conclusions}

All six (three pairs) two-segment models can be used to estimate MFA transition points in an objective manner (by the least squares fit). Each of the three paired models (LIN_C and LIN_LIN), (EXP_C and EXP_LIN), and (Q_C and Q_LIN), obtained essentially the same estimates from the view-point of practical usage. However, the choice of which model (pair) should be suitable for transition demarcation depends on the requirements and risk assessment by the end-user. For progressive determination toward the juvenile phase, LIN_LIN can be used; for conservative estimates toward the mature phase, Q C can be chosen; otherwise, EXP_C may be preferred.

Overall, significant differences in MFA transitions appeared among different sites. The relationship between tree transitions and tree or stand variables (e.g., DBH, HT, $\mathrm{SC}$, and $\mathrm{BAL}$ ) remains inconclusive.

Acknowledgments The authors thank Jared Salvail, John Vallentgoed, Jonathan Martin DeMoor, Dominique Lejour, Calvin Strom, Kirsten Mortensen, and Myriam Suard for their accuracy and commitment in carrying out the field work for this project. Comments on an earlier version by Art Groot, Ted Hogg, and Cosmin Filipescu are greatly appreciated. Discussions with Roger Whitehead, Paul Bicho, Barbara Dalpke, and Maurice Defo helped to shape the direction of this research. The comments of two anonymous reviewers are appreciated for helping improve the clarity of the manuscript.

Funding Funding for this study was provided by the Canadian Wood Fibre Centre, Canadian Forest Service, Natural Resources Canada.

\section{References}

Alteyrac J, Cloutier A, Zhang SY (2006) Characterization of juvenile wood to mature wood transition age in black spruce (Picea mariana (Mill.) B.S.P.) at different stand densities and sampling heights. Wood Sci Technol 40:124-138

Bhat KM, Priya PB, Rugmini P (2001) Characterisation of juvenile wood in teak. Wood Sci Technol 34:517-532

Butterfield B (2003) Wood anatomy in relation to wood quality. In: Barnett JR, Jeronimidis G (eds) Wood quality and its biological basis. Blackwell, Oxford, pp 30-52

Cave ID (1968) The anisotropic elasticity of the plant cell wall. Wood Sci Technol 2:268-278

Clark A III, Saucier JR (1989) Influence of initial planting density, geographical location, and species on juvenile wood formation Southern Pine. For Prod J 39:42-48

Clark A III, Daniels RF, Jordan L (2006) Juvenile/mature wood transition in loblolly pine as defined by annual ring specific gravity, proportion of latewood, and microfibril angle. Wood Fiber Sci 38:292-299

Defo M, Goodison A, Uy N (2009) A method to map within-tree distribution of fibre properties using SilviScan-3 data. For Chron $85: 409-414$

Evans R (1999) A variance approach to the X-ray diffractometric estimation of microfibril angle in wood. Appita J 52:283-294

Evans R, Hugues M, Menz D (1999) Microfibril angle variation by scanning X-ray diffractometry. Appita J 52:363-367

Goudie JW, Di Lucca CM (2004) Modelling the relationship between crown morphology and wood characteristics of coastal western hemlock in British Columbia. In: Nepveu G (ed) Fourth Workshop on the connection between silviculture and wood quality through modelling approaches and simulation software, Harrison Hot Springs, British Columbia, Canada. Equipe de Recherches sur la Qualité des Bois, INRA, Nancy, pp 308-319

Harris JM, Meylan BA (1965) The influence of microfibril angle on longitudinal and tangential shrinkage in Pinus radiata. Holzforschung 19:144-153

Jordan L, Daniels RF, Clark A III, He R (2005) Multilevel nonlinear mixed-effects models for the modelling of earlywood and latewood microfibril angle. For Sci 51:357-371

Larson PR (1969) Wood formation and the concept of wood quality. Bull Yale School For 74:1-54

Larson PR, Kretschmann DE, Clark A III, Isebrands JG (2001) Formation and properties of juvenile wood in southern pines. A synopsis. USDA For Prod Lab, Gen Tech Rep FPL-GTR129

Mansfield SD, Parish R, Goudie JW, Kang K-Y, Ott P (2007) The effects of crown ratio on the transition from juvenile to mature wood in lodgepole pine in western Canada. Can J For Res 37:1450-1499

Mansfield SD, Parish R, Di Lucca CM, Goudie J, Kang KY, Ott $P$ (2009) Revisiting the transition between juvenile and mature wood: a comparison of fibre length, microfibril angle and relative wood density in lodgepole pine. Holzforschung 63:449-456

Medzegue MJ, Greliera S, M'Batchi B, Nziengui M, Stokes A (2007) Radial growth and characterization of juvenile and adult wood in 
plantation grown okoumé (Aucoumea klaineana Pierre) from Gabon. Ann For Sci 64:815-824

Mutz R, Guilley E, Sauter UH, Nepveu G (2004) Modelling juvenilemature wood transition in Scots pine (Pinus sylvestris L) using nonlinear mixed-effects models. Ann For Sci 61:831-841

Peszlen I (1994) Influence of age on selected anatomical properties of Populus clones. IAWA J 15:311-321

Saranpää P (2003) Wood density and growth. In: Barnett JR, Jeronimidis $\mathrm{G}$ (eds) Wood quality and its biological basis. Blackwell, Oxford, pp $87-117$
Sauter UH, Mutz R, Munro BD (1999) Determining juvenile-mature wood transition in Scots pine using latewood density. Wood Fiber Sci 31:416-425

Stewart JD, Jones TN, Noble RC (2006) Long-term lodgepole pine silviculture trials in Alberta: history and current results. Natural Resources Canada, Canadian Forest Service, Northern Forestry Centre, Edmonton, Alta., and Foothills Model Forest, Hinton, Alta. http://cfs.nrcan.gc.ca/publications/?id=26202

Tasissa G, Burkhart HE (1998) Juvenile-mature wood demarcation in loblolly pine trees. Wood Fiber Sci 30:119-127 